\title{
The Processing of Ambiguous Sentences by First and Second Language Learners of English
}

\author{
Claudia Felser ${ }^{a}$, Leah Roberts ${ }^{a}$, Rebecca Gross ${ }^{b}$ \& Theodore Marinis $^{\text {a }}$ \\ ${ }^{a}$ Department of Language and Linguistics \\ University of Essex \\ ${ }^{\mathrm{b}}$ Department of Linguistics \\ University of Düsseldorf
}

[ Revised version appeared in Applied Psycholinguistics 24 (2003), 453-489. ]

\section{Abstract}

This study compares the way English-speaking children and adult second language learners of English resolve relative clause attachment ambiguities in sentences such as The dean liked the secretary of the professor who was reading a letter. Two groups of advanced L2 learners of English with Greek or German as their L1 participated in a set of off-line and on-line tasks. While the participants' disambiguation preferences were influenced by lexical-semantic properties of the preposition linking the two potential antecedent NPs (of vs. with), there was no evidence that they were applying any structure-based ambiguity resolution strategies of the type that have been claimed to influence sentence processing in monolingual adults. These findings differ markedly from those obtained from 6 to 7 yearold monolingual English children in a parallel auditory study (Felser, Marinis, \& Clahsen, submitted) in that the children's attachment preferences were not affected by the type of preposition at all. We argue that whereas children primarily rely on structure-based parsing principles during processing, adult L2 learners are guided mainly by non-structural information. 


\section{Introduction}

Our understanding of how mature readers or listeners process their native language in real time has increased considerably over the last couple of decades. Results from sentence processing studies using a range of different psycholinguistic methods and techniques have shown that the adult parser is capable of accessing and rapidly integrating various types of structural and non-structural information during comprehension (see Gibson \& Pearlmutter, 1998, for review). Comparatively little is known, by contrast, about the way language learners process input from the target language. Instead, both first and second language acquisition research to date has focussed primarily on the development of linguistic competence (compare, for instance, the articles in Ritchie and Bhatia, 1996, 1999). That the question of how language learners process the target language should have received relatively little attention in the past is surprising, though, given that language processing and grammatical development are inextricably linked: Whereas on the one hand, a language learner's ability to process an input string is a crucial prerequisite for grammar building, successful parsing, in turn, presupposes sufficient grammatical knowledge to enable the parser to segment an input string into grammatically meaningful chunks, to assign appropriate category labels to each segment, and to determine hierarchical relationships and intra-sentential dependencies among constituents (for more detailed discussions of this 'acquisition paradox', see Fodor, 1998, or Valian, 1990). With the grammar and the parser being thus entwined in language development, it may be that at least some of the differences in linguistic proficiency that have been observed between children and adults, and between second language learners and native speakers, are attributable to differences in the way language learners and adult native speakers process the target language. As regards first language acquisition, it is conceivable, for example, that children's linguistic development is constrained by capacity limitations of the developing processing system (Adams \& Gathercole, 2000). For adult second language acquisition, it is possible that the lack of ultimate attainment in the L2 is due to parsing problems rather than to an inability to acquire native-like grammatical competence per se, as is often assumed (compare also Juffs \& Harrington, 1995, Kilborn, 1992, or VanPatten, 1996). More specifically, it may be the case that second language learners transfer processing strategies from their native language to the L2, and that this prevents them from acquiring full native-like competence and/or 
fluency in the second language. In short, answers to the question of whether or not children and second language learners process the target language in the same way as adult native speakers do are likely to have important implications for theories of both first and second language acquisition.

One possible answer to the above acquisition paradox has been provided by the Continuity Hypothesis (Crain \& Thornton, 1998, Crain \& Wexler, 1999, Fodor, 1998), according to which human beings are innately equipped not only with a Universal Grammar, but also with a universal set of 'least effort' based language processing routines, or Universal Parser. If the continuity approach is correct, then we do not expect to find any qualitative differences in parsing performance between language learners and adult native speakers, at least not with respect to their use of universal processing strategies. Within universalist models of sentence processing, cross-linguistic variation in parsing is attributed either to factors affecting post-structural processing (compare Frazier \& Clifton, 1996), or is assumed to be restricted to a small set of parameterised processing routines whose settings are directly or indirectly linked to certain language-specific properties of the grammar (Cuetos \& Mitchell, 1988, Frazier \& Rayner, 1988, Gibson, Pearlmutter, CansecoGonzales, \& Hickok, 1996, Mazuka, 1998, Mazuka \& Lust, 1990).

Experience-based models of language acquisition and processing such as the Competition Model (MacWhinney, 1987, 1997, 2001), on the other hand, assume that both linguistic knowledge and language processing routines are acquired through exposure to the target language using domain-independent cognitive strategies only. Form-function mappings are not mediated by symbolic linguistic representations, and the time-course and relative order of acquisition are assumed to be determined by probabilistic factors such as cue strength and cue validity, in conjunction with general cognitive development. Regarding second language acquisition, the Competition Model predicts that L2 learners should transfer the processing strategies from their L1 to the L2, before gradually becoming more native-like in their L2 linguistic performance as the two languages begin to form separate systems.

The present study aims to investigate the extent to which L2 learners are capable of acquiring the processing strategies of the target language, and to compare the processing strategies used by second language learners to those employed by children. The main empirical questions to be addressed are the following: 
- Do children and adult L2 learners employ the same sentence processing strategies as native speakers of the target language do?

- To what extent are language learners capable of using and integrating both structural and non-structural information during processing?

- Is there any evidence that L2 learners transfer processing strategies from their L1?

In order to address the above questions, we have examined the way advanced L2 learners of English from different language backgrounds resolve relative clause attachment ambiguities in two-site contexts, a phenomenon that has been extensively studied with native speakers in the past, and which is known to be subject to cross-linguistic variation. To explore the extent to which child L1 and adult L2 processing are similar (or dissimilar), we will compare our results with those from a parallel study with English-speaking children that has recently been conducted by our research group (Felser et al., submitted).

The remainder of this paper is organised as follows. In the next section we provide a brief overview of cross-linguistic differences in the processing of relative clause attachment ambiguities, the phenomenon under investigation. Section 3 summarises previous findings on ambiguity resolution strategies employed by children, followed by an overview of the results from existing studies examining ambiguity resolution in L2 processing in section 4. Sections 5-8 present the results from four experiments investigating relative clause attachment preferences in different groups of advanced L2 learners of English using both off-line and on-line tasks. The implications of our findings for theories and models of language acquisition and processing are discussed in section 9, and the main findings and conclusions are summarised again in section 10 .

\section{Cross-linguistic variation in parsing}

Cross-linguistic differences between the way structural ambiguities are resolved in a given language indicate that some parsing strategies are language-specific rather than universal, and thus need to be learned through experience. Consider sentence (1) below, which is globally ambiguous in that the relative clause who was on the balcony can legitimately be 
construed either with the noun phrase the servant (= NP1 attachment) or with the actress (= NP2 attachment).

(1) Someone shot the servant of the actress who was on the balcony.

Previous psycholinguistic studies have shown that adult native speakers of English tend to associate the relative clause with the second rather than the first NP (i.e., with the actress) in both off-line (Cuetos \& Mitchell, 1988, Dussias, 2001, Fernández, 1999, Gilboy, Sopena, Clifton, \& Frazier, 1995) and on-line reading comprehension tasks (Carreiras \& Clifton, 1999, Corley, 1995, Fernández, 2000, Henstra, 1996). ${ }^{1}$ A preference for NP1 attachment, in contrast, has been reported for corresponding 'genitive' constructions in numerous other languages including Spanish (Cuetos \& Mitchell, 1988, Carreiras \& Clifton, 1993, Gilboy et al., 1995 - but cf. Fernández, 2000), Dutch (Brysbaert \& Mitchell, 1996), German (Hemforth, Konieczny, \& Scheepers, 2000), French (Frenck-Mestre \& Pynte, 1997, Zagar, Pynte, \& Rativeau, 1997 - but cf. Baccino, De Vincenzi, \& Job, 2000), and Greek (Papadopoulou \& Clahsen, 2001).

Within Gibson and Pearlmutter's (1998) multiple-constraint model of sentence processing, attachment preferences are determined by the relative strength of a number of interacting structural and non-structural factors in a given language. According to Gibson et al. (1996), the NP2 preference that is typically found in English can be explained by assuming that in highly configurational languages like English, ambiguous modifiers are integrated into the current parse in accordance with the locality principle of Recency, which favours attachment of an ambiguous phrase to the most recently processed constituent (and which is similar to the Late Closure strategy proposed earlier by Frazier, 1979, Frazier \& Fodor, 1978).

(2) Recency

Attach new incoming material to the most recently processed phrase if grammatically possible. 
In languages whose speakers prefer NP1 disambiguation, on the other hand, the interacting locality principle of Predicate Proximity, according to which ambiguous modifiers will preferentially be attached to constituents as structurally close as possible to the predicate, or to the S/IP node (hence favouring attachment of the relative clause to the overall object NP in example [1] above), is assumed to be strong enough to outrank the (supposedly universal) Recency preference. ${ }^{2}$

\section{Predicate Proximity}

Attach as structurally close as possible to the head of a predicate phrase.

The set of languages in which NP1 attachment has been shown to be the preferred option also includes German and Greek, the native languages of the two groups of L2 learners examined in the present study. That is, for both the German and the Greek equivalents of (1), native speakers preferentially associate the relative clause with the initial NP in the complex (compare Hemforth et al., 2000, for German, and Papadopoulou \& Clahsen, 2001, for Greek).

In addition to the two structure-based locality principles of Recency and Predicate Proximity, modifier ambiguity resolution is also influenced by lexical-semantic information. Evidence for this can be gathered from the observation that for complex NPs linked by thematic prepositions such as with, NP2 disambiguation is universally preferred over NP1 disambiguation in both off-line (Gilboy et al., 1995) and on-line comprehension tasks (Frenck-Mestre \& Pynte, 2000, Papadopoulou \& Clahsen, 2001, Traxler, Pickering, \& Clifton, 1998). The fact that the presence of a lexically contentful preposition like with elicits a robust NP2 attachment preference even in languages for which an NP1 preference has been attested for complex genitive antecedents suggests that this type of lexical bias is strong enough to override any structure-based locality principle that might otherwise favour NP1 attachment.

A possible explanation for the remarkably robust NP2 preference triggered by with and its translation equivalents in other languages has been offered within the framework of Construal Theory (Frazier \& Clifton, 1996), according to which associating modifying phrases with constituents outside the current thematic domain is computationally costly, 
and hence dispreferred. As prepositions like with - unlike mere case-assigners such as of in (1) above - create a local thematic domain of their own, the construal hypothesis correctly predicts that in sentences such as (4) below, the ambiguous relative clause should preferentially be associated with the second NP, the servant.

$$
\text { Everyone liked the actress [ with THE SERVANT who was always smiling ] }
$$

If the second NP is a genitive-marked or prepositional object of the first NP, however, the current thematic processing domain is the overall object NP, so that from the point of view of the construal hypothesis, either NP1 or NP2 may serve as the antecedent for an ambiguous relative clause.

(5) Someone shot [ THE SERVANT of THE ACTRESS who was on the balcony ].

According to construal theory, disambiguation preferences in contexts containing complex genitive NPs are determined by the interaction of universal, structure-based parsing strategies and other factors potentially affecting attachment. Non-structural factors that have been claimed to influence comprehenders' attachment preferences include prosody (Schafer, Carter, Clifton, \& Frazier, 1996, Fodor, 1998), the availability of alternative structures such as the Saxon genitive (Frazier \& Clifton, 1996), NP-modifiability (Thornton, MacDonald, \& Gil, 1999), anaphoricity of the relativising element (Hemforth et al., 2000), and the frequency of past exposure to each attachment pattern, the so-called Tuning Hypothesis (Cuetos, Mitchell, \& Corley, 1996, Mitchell \& Cuetos, 1991).

\section{Children's processing of ambiguous sentences}

While children's grammatical development is usually assumed to be complete by about age 6 , few studies to date have investigated the development of language processing in young learners, and only a small subset of these have examined children's on-line ambiguity resolution strategies. The latter set of studies - all of which have examined English- 
speaking children - will be summarised briefly below, and their findings will be compared with the results from our study of adult L2 learners later on.

Trueswell, Sekerina, Hill, and Logrip (1999) recorded children's eye movements during the comprehension of sentences containing temporary PP-attachment ambiguities such as Put the frog on the napkin in the box. The authors found that five year-olds preferred to construe the PP on the napkin as the destination argument of put rather than as a modifier of the frog, even if the visual context was manipulated in such as way so as to bias them towards the NP modifier interpretation. This finding suggests that during the processing of PP-attachment ambiguities, children at the age range tested give priority to completing the argument structure of the main predicate, that is, they attach the ambiguous PP to the verb phrase, in accordance with the principle of Minimal Attachment (Frazier, 1979), or Gibson et al.'s (1996) Predicate Proximity strategy. A preference for VP attachment has also been reported in comparable studies with adults (Frazier \& Rayner, 1982, among others). Contrary to adults, however, the children's attachment preferences remained largely unaffected by the situational context (cf. Altmann \& Steedman, 1988, Tanenhaus, SpiveyKnowlton, Eberhard, \& Sedivy, 1995). ${ }^{3}$

Further evidence that children's on-line parsing decisions are influenced primarily by structural information is provided by a reading-time study conducted by Traxler (2002), who tested 8 to 12 year-old children's processing of sentences containing temporary subject/object ambiguities, such as (6a-c) below. Sentences of the type shown in (6a) are known to elicit robust 'garden-path' effects in adult native speakers, which are caused by their misanalysing the postverbal NP as the direct object of an optionally transitive verb, in accordance with the Late Closure principle. Garden-path effects have been found to be ameliorated, however, in sentences such as (6b), in which the postverbal NP is not a plausible object of the verb, and in sentences like (6c) that contain an intransitive verb (compare e.g. Adams, Clifton, \& Mitchell, 1998, Garnsey, Pearlmutter, Myers, \& Lotocky, 1997).

(6) a. When Sue tripped the girl fell over and the vase was broken.

b. When Sue tripped the table fell over and the vase was broken.

c. When Sue fell the policeman stopped and helped her up. 
The children tested in Traxler's study, by contrast, showed a tendency to analyse the postverbal NP in all the above conditions as a direct object, irrespective of plausibility or verb subcategorisation preferences. This finding provides further support for the idea that for children, structure-based 'least effort' principles take precedence over lexical or pragmatic biases.

Using both an auditory questionnaire and a self-paced listening task, Felser et al. (submitted) have investigated relative clause attachment preferences in 6 to 7 year-old English-speaking children. Materials used in the on-line task included sentences such as (7a-d) below, which were disambiguated towards either NP1 or NP2 attachment by number marking on the auxiliary (was vs. were).

(7) a. The doctor recognised the nurse of the pupils who was feeling very tired.

b. The doctor recognised the nurse of the pupils who were feeling very tired.

c. The doctor recognised the pupils with the nurse who were feeling very tired.

d. The doctor recognised the pupils with the nurse who was feeling very tired.

Presenting the materials auditorily rather than visually was necessary as many children at the age range tested are not yet able to read. As previous studies by Ferreira, Henderson, Anes, Weeks, and MacFarlane (1996) and Booth, MacWhinney, and Harasaki (2000) have demonstrated, though, the auditory moving-window technique is equivalent to its visual counterpart with respect to the types of effect it is sensitive to. Felser et al. found that whereas the adult control group's attachment preferences were influenced by the type of preposition joining the two potential antecedent NPs (of vs. with), children's on-line attachment preferences interacted only with their listening span: While children with a relatively high listening span showed a preference for NP1 attachment irrespective of the type of preposition involved, the low-span children showed an across-the-board tendency towards NP2 disambiguation. These results suggest that depending on their working memory capacity, the children preferentially employed either the Predicate Proximity or the Recency strategy. Contrary to the adult controls, however, neither group of children showed any sensitivity to lexical properties of the preposition during processing, as 
witnessed by the absence of any interaction between antecedent type and attachment in the results from the on-line task.

Although the existing body of research into children's processing of ambiguous sentences is too small at present to warrant any firm conclusions, the findings reported above seem to indicate that children are guided predominantly by structural information during processing. That is, children appear to integrate new incoming words or phrases into the current parse in accordance with locality principles such as Recency and Predicate Proximity that are also known to guide sentence processing in adults, while largely disregarding non-structural cues.

\section{Ambiguity resolution in L2 processing}

While results from previous off-line studies suggest that second language learners are similar to native speakers in that they are able to make use of various types of nonstructural cue to L2 sentence interpretation (compare, for instance, Harley, Howard, \& Hart, 1995, Ying 1996), properties of a learner's native language have also been claimed to influence sentence interpretation in the L2 (Harrington, 1987, Kilborn, 1989, Kilborn \& Ito, 1989, McDonald, 1987, among others - see MacWhinney, 1997, for a review of studies within the Competition Model). Comparatively few studies have investigated the way second language learners process sentences from the L2 in real time, though. The following provides a brief overview of existing on-line studies on L2 ambiguity resolution.

Several of these studies have found evidence for the use of verb-based lexical information during L2 processing. In a word-by-word reading-time study, Juffs (1998) examined how L2 learners of English from various language backgrounds process sentences containing reduced relative clause ambiguities such as The bad boys criticized almost every day were playing in the park. The results show that although slower than the native speaker controls, advanced L2 learners processed the experimental sentences in a similar way as did the native speakers. This finding indicates that like native speakers, advanced L2 learners are guided by argument structure information during processing. Similarly, Frenck-Mestre and Pynte (1997) found evidence for the influence of verb subcategorisation information on L2 ambiguity resolution. Using the eye-movement monitoring technique, the authors 
investigated the way advanced English learners of French and French learners of English resolved PP-attachment ambiguities in sentences such as They accused the ambassador of espionage (of Indonesia) but nothing came of it. The results from their first experiment suggest that English learners of French and monolingual French speakers process temporarily ambiguous sentences of this type in essentially the same way, attaching potential argument PPs such as of espionage to the verb phrase, and analysing PPs like of Indonesia as NP modifiers. In a second experiment, Frenck-Mestre and Pynte examined how French learners of English, and English learners of French, processed sentences such as Every time the dog obeyed (barked) the pretty little girl showed her approval that contained a temporary subject/object ambiguity. The results from the English sentences showed that the French readers experienced more difficulty with verbs of the obey type whose subcategorisation frame is different in French than did the English native readers. For the French test items, on the other hand, both participant groups appeared to have some difficulty processing sentences containing verbs that could be used transitively only in English, a finding that according to the authors may be indicative of L2 influence on L1 processing ('backward transfer'). Taken together, their results failed to show any qualitative differences between L1 and L2 ambiguity resolution, save for the observation that the L2 learners tended to be more confused by conflicting verb argument structure information than were native readers.

Although several studies exist that have examined the way L2 learners process relative clause attachment ambiguities in real time, the results obtained thus far are not fully conclusive. In an eye-tracking study, Frenck-Mestre (1997) investigated how English and Spanish L2 learners of French resolved relative clause attachment ambiguities in sentences such as Jean connaît les filles de la gardienne qui partent 'John knows the girls of the nanny who are leaving'. She found that the Spanish L2 learners patterned with French native speakers in that they showed preference for NP1 disambiguation, whereas the English group showed no preference. Given that Spanish but not English speakers also show an NP1 preference in their L1, Frenck-Mestre interprets these results as evidence for the influence of L1 processing strategies on L2 sentence processing.

Somewhat different results were obtained by Fernández (2000) in a self-paced reading task with 'early' Spanish/English bilinguals whose dominant language was either Spanish or 
English. She found that none of the participant groups exhibited any consistent preferences for either NP1 or NP2 attachment when processing temporarily ambiguous sentences such as Andrew had dinner yesterday with the nephews of the teacher that was divorced, or their Spanish equivalents. Given that Fernández had found an initial NP2 preference for both English and Spanish monolingual speakers in a parallel experiment, the results from the bilinguals cannot be explained in terms of L1 processing transfer, or by the assumption that bilinguals use an amalgamated set of processing routines (Fernández, 2000, p. 281). To complicate the emerging overall picture further, results from a similar study reported in Dussias (2001) indicate that Spanish/English bilinguals who learned English in adulthood but not 'early' bilinguals - are able to acquire an English-like NP2-attachment strategy.

Further evidence against the transfer of L1 processing strategies has been provided by Papadopoulou and Clahsen's (2001) study of L2 processing in Greek. Also using a segment-by-segment self-paced reading task, Papadopoulou and Clahsen compared the relative clause attachment preferences of Spanish, German and Russian L2 learners of Greek with those of Greek native speakers. Experimental materials included sentences such as (8a) and (8b) below that contained complex NPs followed by a temporarily ambiguous relative clause introduced by the complementiser $p u$ 'that'. The second potential host NP either carried morphological genitive case (tis kathigitrias 'the teacher' in [8a]) or was the complement of the thematic proposition me 'with' (cf. [8b]). The disambiguating information forcing either NP1 or NP2 attachment was provided by gender marking on the participle (apogoitevmenos 'disappointed-MASC' vs. apogoitevmeni 'disappointed-FEM') in all four conditions.

a. Enas kirios fonakse ton fititi tis kathigitrias pu a man called the-MASC student-MASC the-FEM teacher-FEM that itan apogoitevmenos / apogoitevmeni apo to neo ekpedeftiko sistima. was disappointed-MASC disappointed-FEM by the new educational system

'A man called the (male) student of the (female) teacher who was disappointed (masc./fem.) by the new educational system.' 
b. Enas kirios fonakse ton fititi me tin kathigitria pu a man called the-MASC student-MASC with the-FEM teacher-FEM that itan apogoitevmenos /apogoitevmeni apo to neo ekpedeftiko sistima. was disappointed-MASC disappointed-FEM by the new educational system

'A man called the (male) student with the (female) teacher who was disappointed (masc./fem.) by the new educational system.'

Papadopoulou and Clahsen found that while the L2 learners performed similarly to the native speakers as far as their NP2 preference for complex NPs linked by the proposition me 'with' was concerned, they differed from the native speaker controls in that neither group exhibited any clear preferences for complex genitive NPs. These findings suggest that despite their high level of competence in the target language (as was demonstrated independently by the results from two off-line judgement tasks), L2 learners of Greek process the experimental sentences differently to native speakers. Interestingly, these results also show that even though an NP1 preference has been attested for complex genitive NPs both for the learners' native languages and for the target language, neither group of L2 learners appears to have transferred the NP1 attachment preference from their L1. The authors argue that their findings are incompatible with purely exposure-based accounts of the acquisition of parsing preferences such as the Tuning Hypothesis (Cuetos et al., 1996, Mitchell \& Cuetos, 1991), which predict that after an initial stage of transfer, second language learners will gradually come to acquire the parsing preferences of the target language as proficiency increases.

In summary, the above studies suggest that even advanced L2 learners do not process complex sentences in quite the same way as adult native speakers do, at least as far as their use of structure-based parsing strategies is concerned. The extent to which L1 ambiguity resolution strategies influence processing in the L2 is still unclear. Like native speakers, however, second language learners seem to be able to make use of lexical-semantic cues such as verb argument structure information, or the NP2 attachment cue provided by thematic prepositions such as with, during L2 processing.

The present study builds on the above findings, and aims to further investigate whether advanced L2 learners are capable of acquiring the processing strategies of the target 
language, and the extent to which second language learners are influenced by structural and non-structural information during L2 processing. In the following, we present the results from a set of off-line questionnaire and on-line reading-time experiments investigating the way advanced German and Greek L2 learners of English resolve relative clause attachment ambiguities in the target language. Since German and Greek both differ from English in that they belong to the group of languages for which an NP1 preference has been attested for complex genitive antecedents, investigating L2 learners from these language backgrounds should help us determine whether or not second language learners are able to acquire L2 parsing strategies that are different from those found in their L1, or whether L1 processing strategies are transferred to the L2. Choosing English as the target language will enable us to compare and contrast our results with those obtained from English-speaking children in a similar auditory study.

\section{Experiment I}

\subsection{Method}

Participants. 28 advanced German learners of English (mean age 26.5, range 18-47, 21 female), all of them students at the University of Düsseldorf, Germany, participated in this experiment. All participants had normal or corrected-to-normal vision, and were naïve with respect to the purpose of the study. All but one of the German participants had first been exposed to English around the age of 10 (mean age of first exposure $=10, \mathrm{SD}=1.54$ ), and had had previous formal instruction in English in Germany, for a period ranging from 6 years to 13 years $($ mean $=9.5$ years, $S D=1.6)$. One of the participants reported that he had first been exposed to English at about age 4, but like the others, he did not consider himself bilingual. The participants' general level of proficiency in English was assessed prior to the main experiment using the grammar part of a standardised proficiency test (Oxford Placement Test; Allan, 1992). All participants scored 71\% or higher (range $=71 \%-95 \%$ ) in this test, indicating that all of them were advanced learners of English. The L2 learners also underwent a grammaticality judgement test, the main purpose of which was to test their knowledge of the construction under investigation, including subject-verb agreement (as this was later used for grammatical disambiguation in Experiment II). The materials for 
the grammaticality judgement test comprised a total of 64 sentences, including 24 experimental (12 grammatical, 12 ungrammatical) and 40 filler sentences. The critical test sentences all contained a complex object NP followed by a relative clause, as in The headmaster smiled at the pupils of the teachers who were standing in the hall. The participants were instructed to read the sentences that were presented to them on a questionnaire sheet carefully, to indicate for each sentence whether or not it contained a grammatical error, and to mark the error in all sentences they considered ungrammatical. All participants judged $79 \%$ or above (range $=79 \%-100 \%$ ) of the critical items correctly in this task, suggesting that they had acquired near-native or native-like knowledge in this area of English grammar. Table 1 summarises the results from the two pretests.

Table 1: $\quad$ Mean proficiency and grammaticality judgement scores from the German L2 learners

\begin{tabular}{||l|c|c||}
\hline & Mean & SD \\
\hline \hline Oxford Placement Test (Grammar only) & $85 \%$ & 7 \\
\hline \hline Grammaticality Judgement Test: Total Score & $92 \%$ & 4 \\
\hline Critical Items - Hits & $92.3 \%$ & 13.6 \\
\hline Critical Items - Correct Rejections & $92.8 \%$ & 9.3 \\
\hline
\end{tabular}

The fact that the participants were able to identify agreement errors correctly demonstrates that they can handle subject-verb agreement in the target language.

Materials. The questionnaire materials included 40 sentences in total (20 experimental, 20 fillers). All experimental sentences were structurally ambiguous and of the form $N P-V$ [NP1-P-NP2]-RC. There were two versions of each sentence, with two noun phrases in the NP complex being joined either by functional/occupational of or by 'accompaniment' with, as illustrated by (9a) and (9b) respectively. Both NPs and the auxiliary in the relative clause appeared in the singular. 
(9) a. The dean liked the secretary of the professor who was reading a letter.

b. The dean liked the professor with the secretary who was reading a letter.

In order to make the experimental sentences sound equally natural in both the of and the with conditions, we reversed the relative ordering of NP1 and NP2 in the with conditions. ${ }^{4}$ All NPs used in the experimental sentences had human referents, with each pair of nouns appearing in the NP-P-NP complex being matched for frequency. Two different versions of the questionnaire were created with each set containing one version of each experimental sentence only. Each version of the questionnaire contained an equal number of of and with sentences, and all items were pseudo-randomised. ${ }^{5}$

Procedure. Participants were instructed to read the sentences carefully and then to indicate for each sentence which of two possible interpretations they considered the more appropriate one. Compare the example in (10) below for illustration.

(10) The dean liked the secretary of the professor who was reading a letter.

$i$. the secretary was reading a letter

ii. $\quad$ the professor was reading a letter

In half of the choices, NP1 in the complex appeared first, and in the other half, it appeared second, to avoid the subjects developing a strategy for answering the questions. Although the participants were able to read the sentences more than once, they were instructed to make their choices as spontaneously as possible.

\section{$5.2 \quad$ Results}

Table 2 presents the mean percentages of NP2 responses provided for each of the two antecedent types. 
Table 2: $\quad$ Mean percentages of NP2 responses, Experiment I

\begin{tabular}{|l|c|c||}
\hline & Mean & SD \\
\hline \hline NP1-of-NP2 & $52 \%$ & 28.1 \\
\hline NP1-with-NP2 & $87 \%$ & 14.4 \\
\hline
\end{tabular}

While the participants showed an above-chance preference for NP2 disambiguation for the with condition, they produced an about equal number of NP1 and NP2 responses for complex genitive NPs. The relatively high standard deviation for responses to the ofcondition moreover indicates considerable within-participant variation for this condition. A one-way ANOVA with the factor Preposition ( of vs. with) revealed a significant main effect of Preposition $(\mathrm{F} 1(1,27)=67.913, \mathrm{p}<0.001 ; \mathrm{F} 2(1,19)=60.172, \mathrm{p}<0.001)$, confirming that the participants' preference for NP2 attachment was significantly stronger for NPs linked by the preposition with.

\section{Experiment II}

\subsection{Method}

Participants. The same 28 German learners of English that participated in Experiment I also took part in Experiment II. The two experiments were carried out on separate days, with one or more days between experimental sessions.

Materials. The materials used in Experiment I and Experiment II were similar but not identical. The stimulus materials for the self-paced reading task comprised 154 sentences in total, including 10 practice sentences, 48 experimental and 96 filler sentences. The experimental sentences included unambiguous versions of the sentences that were used in Experiment I, plus another four items of the same type. All experimental sentences were temporarily ambiguous and contained a relative clause modifying either the head of the overall object NP (= NP1 Attachment) or the embedded noun phrase (= NP2 Attachment). Disambiguation was forced by number marking on the auxiliary (was vs. were). The two 
critical NPs were joined by either of or with, yielding a total of four experimental conditions.

\section{(11) a. NP1 Attachment (of)}

The dean liked the secretary of the professors who was reading a letter.

\section{b. NP2 Attachment (of)}

The dean liked the secretary of the professors who were reading a letter.

\section{c. NP1 Attachment (with)}

The dean liked the professors with the secretary who were reading a letter.

\section{d. NP2 Attachment (with)}

The dean liked the professors with the secretary who was reading a letter.

The order of the two critical NPs was reversed in the with conditions, and the relative ordering of singular and plural NPs was counterbalanced across all four conditions. Two different experimental sets were created, each of which contained one of and one with version of each experimental sentence (either (11a) \& (11d), or (11b) \& (11c)). The test items in each set were pseudo-randomised and mixed with the fillers.

Procedure. To obtain an on-line record of the unfolding parse, we used the (noncumulative) moving-window technique described by Just, Carpenter, and Woolley (1982). In this task, participants read a sentence in a segment-by-segment fashion by pressing a pacing button in order to receive subsequent words or phrasal segments. The basic rationale underlying the self-paced reading technique is that increased reaction times to a particular segment (compared to the same segment in a control condition) indicate a relatively higher processing difficulty at this point during the parse. That is, reading times to the disambiguating segment should be higher for those conditions that force the dispreferred attachment, reflecting the time it takes comprehenders to revise their initial (i.e., preferred) analysis of the sentence. Participants were seated in front of a 17" monitor, and instructed to read the sentences as quickly and as carefully as possible. The sentences were presented in a segment-by-segment fashion, with each sentence being divided into five segments as 
indicated in (12) below. The disambiguating auxiliary always appeared as the fourth segment.

(12) The dean liked / the secretary of the professor / who / was / reading a letter.

The complex noun phrase was presented as one segment so as to minimise the possibility of the initial NP fading from short-term memory during the processing of the second one, which might bias participants towards NP2 attachment. The participants were instructed to read the sentences carefully and as quickly as possible by pressing a button on a pushbutton box as soon as they were ready to receive the next segment. The presentation of the stimuli and the recording of reaction times was controlled by the NESU software package (Baumann, Nagengast, \& Klaas, 1993). The self-paced reading experiment lasted approximately 30-45 minutes in total, and was divided into two sessions by a short break. The first session was preceded by 10 practice sentences. Each participant read two different sentences from each sentence quadruplet, one in the first session and the other one in the second session. To ensure that the participants made an active effort to comprehend the experimental sentences, all critical sentences and half of the fillers were followed by a yes/no comprehension question which the participants responded to by pushing the corresponding buttons on a dual push-button box.

\subsection{Results}

The overall response accuracy rate was good, with the participants answering $84.42 \%$ (SD $=11.35)$ of the questions to the experimental items correctly, indicating that they were paying attention to the task. Prior to the analysis of the reaction time data, we removed the data from one participant whose overall response accuracy rate was close to chance $(57 \%$ correct), and more than 2SD below the group mean. Only reading times from trials that were responded to correctly were included in the statistical analysis. Two items had to be excluded from the analysis because of a computer error. None of the remaining trials exceeded the set timeout of double the mean total reading time per condition. In order to eliminate individual outliers, we further excluded reading times above or below 2SD from the group's mean for each condition, leading to the exclusion of $7 \%$ of the remaining total 
data. The remaining data from 27 participants were included in the statistical analysis. Table 3 provides an overview of the participants' mean raw reading times to each segment for the four conditions. Here and in the following, all reaction times are given in milliseconds.

Table 3: Mean reading times per condition for all segments, Experiment II

\begin{tabular}{||l||c|c|c|c|c||c||}
\hline & Segment 1 & Segment 2 & Segment 3 & Segment 4 & Segment 5 & TOTAL \\
\hline \hline Of-NP1 & 843 & 1309 & 522 & 435 & 918 & 4027 \\
\hline Of-NP2 & 838 & 1393 & 498 & 439 & 938 & 4106 \\
\hline With-NP1 & 826 & 1334 & 511 & 502 & 887 & 4060 \\
\hline With-NP2 & 835 & 1356 & 512 & 428 & 876 & 4007 \\
\hline \hline
\end{tabular}

No statistical effects or interactions were found for any of the three segments preceding the disambiguating auxiliary. At the disambiguating fourth segment, NP2 attachment elicited substantially shorter reaction times than did NP1 attachment for the with conditions only (428 vs. $502 \mathrm{~ms}$ ). A $2 * 2$ ANOVA with the factors Preposition (of vs. with) and Attachment (NP1 vs. NP2) showed a significant main effect of Attachment $(\mathrm{F} 1(1,26)=11.576, \mathrm{p}=$ $0.002 ; \mathrm{F} 2(1,21)=9.881, \mathrm{p}=0.005)$, reflecting the fact that on average, NP1 attachment elicited longer reaction times than did NP2 attachment, as well as a significant interaction of Preposition vs. Attachment $(\mathrm{F} 1(1,26)=7.674, \mathrm{p}=0.010 ; \mathrm{F} 2(1,21)=5.519, \mathrm{p}=0.029)$. Subsequent pairwise comparisons showed that the difference between NP1 and NP2 attachment was statistically reliable only for the preposition with $(\mathrm{t} 1(1,26)=3.872, \mathrm{p}=$ $0.001 ; \mathrm{t} 2(1,21)=4.132, \mathrm{p}<0.001)$. That is, contrary to the NP2 preference typically found for English native speakers, the German L2 learners did not show any on-line attachment preferences at all for relative clauses following complex NPs linked by of. We further found a main effect of Preposition in the reaction times to Segment 5 that reached significance in the by-participant analysis $(F 1(1,26)=6.173, p=0.020 ; F 2(1,21)=0.607$, $p=0.444)$, and which reflects the fact that overall, the final segment was read faster in the with conditions than in the of conditions. 


\subsection{Discussion}

The results from Experiments I \& II demonstrate that second language learners are sensitive to the NP2 attachment cue provided by the preposition with when resolving relative clause attachment ambiguities in the L2. Contrary to the NP2 preference that has been found for monolingual English speakers, though, the German L2 learners did not show any attachment preference at all for complex genitive NPs in either the off-line or the on-line task. The observation that in the self-paced reading task, the participants spent more time reading the final 'wrap up' segment in the of conditions might indicate that it took them somewhat longer to construct a coherent representation for the sentence as a whole in these conditions. These results suggest that despite their native-like grammatical knowledge of the construction under investigation, the L2 learners process ambiguous sentences differently to native speakers. What is more, the German participants' lack of any preference for the of conditions could be taken to indicate that the L2 learners did not transfer the NP1 preference from their native language to the L2, either. The latter conclusion, however, must be treated with some caution given that in addition to morphological genitives, a more direct equivalent of the Norman genitive is also available in (colloquial) German, which is exemplified in (13) below:

Jemand erschoß die Dienerin von der Schauspielerin, die auf dem Balkon war. someone shot the maid of the actress who on the balcony was

While little is known about German speakers' on-line attachment preferences for sentences such as (13), preliminary results from an off-line study conducted by Gross (2002) suggest that German comprehenders do not have any clear attachment preferences for NPs linked by von. Given this potential confound, then, the results from the first two experiments do not allow us to rule out completely the possibility that the L2 learners' lack of any preference for NPs linked by of is due to L1 influence. In the following two experiments, we eliminated this potential confound by investigating L2 learners with Greek rather than German as their L1. In Greek, a language that is less closely related to English typologically than German, only morphological genitives can function as the equivalent of the English of-NPs in constructions of the type under investigation. As the results from 
Papadopoulou and Clahsen's (2001) study have shown, Greek native speakers preferentially associate ambiguous relative clauses with the initial NP, in accordance with the Predicate Proximity principle.

\section{Experiment III}

\subsection{Method}

Participants. 39 Greek learners of English (mean age =22.4, range =19-35, 18 female), all of them students at the University of Essex, U.K., participated in Experiment III. All participants had normal or corrected-to-normal vision, and were not informed of the ultimate purpose of the study. At the time of testing, all participants had been living in Britain for a period ranging from 5 months to 5 years $($ mean $=1.7, \mathrm{SD}=1.3)$, and all had received previous formal instruction in English in Greece, for a period ranging from 6 years to 14 years $($ mean $=8.9, \mathrm{SD}=2.5)$. All participants reported that they had first been exposed to English at school, with the average age of first exposure being 13.5 years $(\mathrm{SD}=$ 3.97, range 6-28). Like the German L2 learners who took part in the previous two experiments, the Greek participants underwent a general language proficiency test as well as a grammaticality judgement test. The main function of the latter was to determine that the participants were able to handle relative clause constructions with complex antecedents, and specifically, whether they could detect number agreement violations between either of the antecedents in the noun complex and the auxiliary verb in the following relative clause. The Greek L2 learners were all classified as advanced learners of English on the basis of their scores in the grammar part of the Oxford Placement Test (range $=70 \%$ - 97\% correct). The design of the grammaticality judgement task was adapted from Hawkins and Chan (1997). Materials included 50 sentences in total (25 grammatical, 25 ungrammatical), all of which were relative clause constructions of various types. Ten of the test items were structurally identical to the experimental sentences used in the main experiment, with half of these containing subject-verb agreement violations. The participants were asked to read the sentences that were presented to them on a questionnaire sheet and to rate the grammaticality of each sentence on a four-point scale, or else to tick the 'don't know' option. After excluding all 'don't know' responses (less than $1 \%$ of the total number of 
responses), correctness scores were calculated by assigning a score of 3 to the answer 'definitely correct', a score of 2 to the answer 'probably correct', a score of 1 to the answer 'probably incorrect', and a score of 0 to the answer 'definitely incorrect' for the grammatically correct items, and vice versa for the incorrect ones. The maximum possible score for the critical grammatical and ungrammatical items was 15 . The participants also performed very well in this task, scoring an average of 10.6 (range $=5-15$ ) on the critical grammatical items and 13.2 (range $=9-15$ ) on the critical ungrammatical ones (these scores were later converted to percentages). This result demonstrates that the participants were able to handle different types of English relative clause construction, including those of the kind that were used in the main experiment, and that they were sensitive to number agreement violations. Table 4 presents a summary of the participants' scores in the two pretests. $^{6}$

Table 4: $\quad$ Mean proficiency and grammaticality judgement scores from the Greek L2 learners

\begin{tabular}{||l|c|c||}
\hline & Mean & SD \\
\hline \hline Oxford Placement Test (Grammar only) & $83.5 \%$ & 7.6 \\
\hline \hline Grammaticality Judgement Test: Total Score & $76.7 \%$ & 7.3 \\
\hline Critical Items - Hits & $70.4 \%$ & 17.3 \\
\hline Critical Items - Correct Rejections & $87.7 \%$ & 11.9 \\
\hline
\end{tabular}

Materials. The questionnaire materials consisted of 20 experimental sentences and 20 fillers. All experimental sentences and half of the fillers were ambiguous, and there were two versions of each experimental sentence (with NPs linked by either of or with). As before, the relative order of the two NPs in the complex was reversed in the with condition so as to make the sentences sound more natural (compare note 4). All potential host NPs in the test sentences were [+human], and the matrix predicate was always of a type which could pragmatically relate only to the initial NP in the complex, e.g. think about, frown at. Different versions of the questionnaire were constructed so as to ensure that each participant saw one version of each sentence only, and the test items were pseudo- 
randomised. All questionnaire items were followed by a question and two possible answer options, and the subjects were asked to indicate their preferred interpretation.

Procedure. The experimental procedure was identical to that of Experiment I.

\subsection{Results}

Table 5 presents the mean percentages of NP2 responses elicited by the of and the with conditions respectively.

Table 5: $\quad$ Mean percentages of NP2 responses, Experiment III

\begin{tabular}{||l|c|c||}
\hline \hline & Mean & SD \\
\hline \hline NP1-of-NP2 & $51 \%$ & 25.9 \\
\hline NP1-with-NP2 & $82 \%$ & 16.2 \\
\hline
\end{tabular}

Like the German group in Experiment I, the Greek participants showed a clear preference for NP2 disambiguation for complex NPs joined by with but not for complex genitive NPs, indicating that their interpretation preferences were affected by the type of linking preposition. This observation was shown to be statistically reliable by a one-way ANOVA which revealed a significant main effect of Preposition $(\mathrm{F} 1(1,38)=51.590, \mathrm{p}<0.001 ; \mathrm{F} 2$ $(1,19)=32.122, \mathrm{p}<0.001)$. As in Experiment I, responses to the of condition showed a higher degree of within-participant variation than did responses to the with sentences, as witnessed by the difference between standard deviations.

\section{Experiment IV}

\subsection{Method}

The participants were the same as in the previous experiment. The two experiments took place on different days, with at least a week in between sessions. Unambiguous versions of the experimental sentences that were used in the questionnaire study were also used in the 
self-paced reading task, with four more test items added. The participants saw 10 practice items, followed by 96 sentences, 24 of which were experimental sentences pseudorandomly set within 72 filler items of various sentence types. As in Experiment II, all test items were syntactically disambiguated by number on the auxiliary in the relative clause, and the relative ordering of singular and plural antecedents was counterbalanced across the four experimental conditions. Different versions of the experiment were created, so that each subject saw all four conditions but never received the same sentence twice. The selfpaced reading experiment took about 30-50 minutes, depending on how much of a break the participants chose to take during the session. All remaining details of the experimental procedure were identical to those of Experiment II.

\subsection{Results}

Overall, the participants answered $85.6 \%(\mathrm{SD}=13.67)$ of the comprehension questions following the experimental items correctly. All incorrect trials were eliminated prior to the statistical analysis. In addition, the data from two participants were excluded whose response accuracy rate fell more than $2 \mathrm{SD}$ below the group mean. By way of eliminating outlier data, we excluded complete trials whose total reading times exceeded double the group mean for that condition (affecting $1.6 \%$ of the remaining total data), as well as individual reaction times beyond 2SDs from the group's mean for each condition, which led to the further exclusion of $4.5 \%$ of the data. The remaining data from 37 participants were included in the statistical analysis. Table 6 provides an overview of the mean reading times per segment for each condition for both groups.

Table 6: Mean reaction times per condition for all segments, Experiment IV

\begin{tabular}{||l||c|c|c|c|c|c||}
\hline & Segment 1 & Segment 2 & Segment 3 & Segment 4 & Segment 5 & TOTAL \\
\hline \hline Of-NP1 & 1304 & 2840 & 583 & 508 & 1113 & 6348 \\
\hline Of-NP2 & 1391 & 2538 & 631 & 533 & 1081 & 6174 \\
\hline With-NP1 & 1327 & 2451 & 668 & 661 & 1139 & 6246 \\
\hline With-NP2 & 1286 & 2648 & 660 & 532 & 1202 & 6328 \\
\hline
\end{tabular}


There were no significant effects or interactions on the first three segments. The L2 learners' reaction times to the disambiguating auxiliary in segment 4 were shorter in the NP2 condition only for NPs linked by the preposition with (532 vs. $661 \mathrm{~ms}$ ). A $2 * 2$ ANOVA with the factors Preposition (of vs. with) and Attachment (NP1 vs. NP2) revealed a significant main effect of Preposition $(F 1(1,33)=5.371, p=0.027 ; F 2(1,23)=4.984, p$ $=0.036$ ), as well as an interaction of Preposition vs. Attachment that was significant in the by-participant analysis and which approached significance in the by-item analysis (F1 $(1,33)=7.276, p=0.011 ; F 2(1,23)=3.398, p=0.078)$. Subsequent paired t-tests revealed significant differences between NP1 and NP2 attachment for the with conditions (t1 (33)= $2.231, \mathrm{p}=0.033 ; \mathrm{t} 2(23)=2.155, \mathrm{p}=0.042)$ but not for the of conditions. No main effects or interactions were found on the final segment.

The results from the on-line experiment mirror those of the questionnaire study. In both the off-line and the on-line task, the Greek L2 learners showed a marked preference for NP2 attachment for complex NPs linked by with but not for complex genitive NPs, indicating that their initial attachment preferences were influenced by the type of preposition linking the two potential antecedent NPs. Contrary to the NP2 bias typically found for English native speakers, though, the Greek participants exhibited no attachment preferences for complex genitive NPs in either task.

\section{General Discussion}

Our main results can be summarised as follows:

- In both the questionnaire and the self-paced reading tasks, the two groups of L2 learners showed a strong preference for NP2 disambiguation for NPs linked by the preposition with.

- $\quad$ Neither the German nor the Greek L2 learners showed any attachment preferences at all for sentences containing complex genitive antecedents in either task.

These results differ markedly from those obtained from 6 to 7 year-old English-speaking children in Felser et al.'s (submitted) study. Recall that depending on their listening-span scores, the children showed a preference for either NP1 or NP2 disambiguation irrespective 
of the type of preposition linking the two potential antecedent NPs. These differences between the way children and second language learners process relative clause attachment ambiguities may be indicative of qualitative differences between child L1 and adult L2 processing. In what follows, we discuss the implications of our findings for theories of language acquisition and processing.

\section{Use of structural vs. non-structural information during parsing}

Recall that mature speakers' relative clause attachment preferences are determined by at least two interacting parsing strategies, a universal Recency preference, and a principle such as Predicate Proximity that favours attachment to the initial NP. Previous results from adult native speakers indicate that Recency takes precedence over Predicate Proximity for ambiguous relative clauses in two-site contexts in English, whereas Predicate Proximity outranks Recency in languages such as German or Greek that have a less restricted word order than English (compare Gibson et al., 1996). In addition, there is evidence from both off-line and on-line studies suggesting that adult speakers' attachment decisions are also affected by the type of preposition, with NP2 attachment being preferred crosslinguistically for NPs joined by the preposition with.

Our results demonstrate that like native speakers, L2 learners are influenced by the type of linking preposition during the processing of relative clause attachment ambiguities, indicating that adult L2 learners can access and make use of lexical-semantic information during on-line sentence comprehension. This finding is compatible with the results from Juffs' (1998) and Frenck-Mestre and Pynte's (1997) studies that have demonstrated L2 learners' sensitivity to verb argument structure information during processing. There is no evidence from our results, on the other hand, that L2 learners apply either of the two structure-based locality principles (Recency or Predicate Proximity) when processing ambiguous sentences containing complex NPs joined by functional/occupational of. The hypothesis that second language learners' ability to make use of structural information during L2 processing might be reduced relative to that of native speakers is also supported by the results from recent ERP studies carried out by Hahne (2001) and Hahne and Friederici (in press) on Russian and Japanese learners of German. They found that while there were only quantitative differences between the L2 learners and the native speakers 
with respect to the 'N400' ERP component thought to reflect semantic integration difficulty, there were qualitative differences between the groups with respect to the presence of ERP components associated with first-pass parsing ('Early Anterior Negativity', Hahne, 2001) or later syntactic processes ('P600', Hahne \& Friederici, in press).

Given that all our participants had scored very highly on both the language proficiency and the grammaticality judgement tests, it is unlikely that their non-native like performance in our experiments should have anything to do with insufficient grammatical knowledge of the construction under investigation. Thus a more feasible possibility might be that learners have difficulty integrating structural and non-structural information when processing their L2 (Kilborn, 1992), perhaps due to the increased working memory demands posed by reading in a non-native language (Harrington, 1992). An explanation in terms of a processing problem due to resource limitations, however, would seem to make the incorrect prediction that when given more time for interpreting ambiguous sentences (i.e., in off-line tasks), advanced L2 learners should exhibit the same disambiguation preferences as native speakers do. In other words, the finding that our participants also failed to show any attachment preferences for complex genitive NPs in the questionnaire task is unexpected under the assumption that L2 learners have problems integrating different types of information in situations where processing or memory resources are short.

The results from the present study differ from those obtained from 6 to 7 year-old Englishspeaking children in Felser et al.'s (submitted) study in that the L2 learners but not the children were influenced by lexical-semantic information during processing. Instead, the children were found to apply either the Recency or the Predicate Proximity strategy for both types of antecedent NPs in the on-line task. The results from the children are in line with Traxler's (2002) and Trueswell et al.'s (1999) findings that children largely ignore semantic or contextual information during the processing of ambiguous sentences. The observed differences between child L1 and adult L2 learners of English suggest that whereas children predominantly rely on structural information during processing, L2 learners are guided primarily by meaning. 


\section{The role of transfer in 22 processing}

Given that adult second language learners already possess a fully-fledged processing system for their L1, it is conceivable that processing strategies from the L1 are transferred to the L2. There is no evidence from our results to suggest that German or Greek L2 learners have transferred the NP1 preference for complex genitive NPs from their native language, though, given that the L2 learners exhibited no preferences for the of conditions at all. Note that the two groups of L2 learners showed the same pattern of preferences regardless of whether they were fully immersed in the L2 at the time of testing (like the Greek participants) or not (like the German group). One might be tempted to argue, however, that both the German and Greek participants were at a stage 'in between' transferring the NP1 preference from their native languages and acquiring the NP2 preference of the target language, a situation that proponents of the Competition Model refer to as amalgamation (compare Hernandez, Bates, \& Avila, 1994). An explanation along these lines is called into question, however, once we take into account the findings from Papadopoulou and Clahsen's (2001) study on L2 ambiguity resolution by second language learners of Greek. Their results argue against an intermediate stage in L2 processing as the learners they tested failed to show any attachment preferences for complex genitive antecedents even though both the target language (Greek) and the participants' L1's (Spanish, German, and Russian) favour NP1 attachment. Interestingly, our L2 learners showed exactly the same pattern of attachment preferences as did the Spanish, German and Russian learners of Greek examined by Papadopoulou and Clahsen, despite the fact that the two target languages, English and Greek, differ with respect to native speakers' disambiguation preferences. Recall that Fernández (2000) also observed a lack of attachment preferences in Spanish/English bilinguals, even though she had found an initial NP2 advantage for complex genitive antecedents in a parallel study of Spanish and English monolinguals. Together, the results from these studies demonstrate that while being sensitive to lexical-semantic cues provided by the linking preposition, L2 learners show a systematic lack of any clear attachment preferences for relative clauses preceded by complex genitive NPs, irrespective of the preferences found in the target language or in the learners' L1. Note that purely exposure-based models of language acquisition, or models that predict L1 transfer of processing strategies, have difficulty accounting for these 
findings. Rather, it is conceivable that instead of transferring the Predicate Proximity (or Recency) strategy from their native language to the L2, second language learners postpone associating an ambiguous relative clause with either of the two potential host NPs until other (non-structural) cues to interpretation become available. ${ }^{7}$

\section{Continuity in language processing}

According to the continuity view, language learners should employ the same universal parsing strategies that adult native speakers use when processing their target language. While our results provide evidence that advanced second language learners make use of lexical-semantic cues when processing the $\mathrm{L} 2$, there is nothing in our results to suggest that they apply either the Recency or the Predicate Proximity strategy in situations where lexical-semantic information does not bias them towards any particular attachment. Note that if the learners' NP2 preference for complex antecedents joined by with reflected their use of a structure-based Recency strategy, we would expect them to show an NP2 preference for complex genitive NPs as well. The results from Felser et al.'s child study, on the other hand, indicate that whereas children at the age range tested are not sensitive to lexical-semantic biases during processing, they nevertheless employ the same structuredependent parsing strategies that have also been attested for adult native speakers, in accordance with the predictions of the continuity hypothesis. By way of accounting for children's reduced ability to integrate structural and non-structural cues to ambiguity resolution, Felser et al. hypothesize that this may be due to children's relatively limited processing or working memory capacity. Evidence that children are not generally insensitive to contextual information during language use can be gathered from the results from Hurewitz, Brown-Schmidt, Thorpe, Gleitman, and Trueswell's (2000) sentence production task. Using materials similar to those used in Trueswell et al. (1999) study of PP-attachment ambiguity (compare section 3 above), Hurewitz et al. demonstrated that children are quite capable of taking into account information provided by the referential context in a task that puts less demand on the child's processing resources than on-line sentence comprehension does.

Do the observed differences between native speakers and L2 learners mean, then, that L2 processing is qualitatively different from L1 processing? Our results would seem to suggest 
that this is indeed the case. Note that the possibility that L2 learners should simply require more time than native speakers do for revising their initial attachment decision in the conditions forcing the dispreferred attachment is unlikely given that we found no significant differences between NP1 and NP2 attachment on the final segment, either, and that our participants also failed to show any disambiguation preferences in the off-line task. Rather, our results support the hypothesis that L2 learners do not rely on syntactic information to the same extent that native speakers do when processing input from the target language, and instead attempt more direct form-function mappings (compare also Gass, 1986, Pienemann, 1998). More specifically, it is conceivable that contrary to the L1 parser, the L2 sentence comprehension mechanism does not integrate incoming ambiguous words or phrases immediately into the current syntactic analysis, but instead delays the attachment decision until other information becomes available that helps disambiguate the sentence. This would explain why the appearance of the disambiguating auxiliary did not cause any processing disruption in either of the complex genitive conditions in the on-line task, and why our participants did not show any disambiguation preferences at all for the globally ambiguous $N P 1-o f-N P 2$ sentences used in the off-line task. With respect to their use of structure-based first-pass parsing strategies in ambiguity resolution, then, second language learners seem to differ radically from child L1 learners, who show evidence of being able to apply structural locality principles during on-line comprehension, while largely disregarding non-structural cues to sentence interpretation. Our finding that even highly proficient L2 learners process input from the target language differently to native speakers suggests that it may be processing problems that prevent 'late' L2 learners from ever achieving full native-like competence in the L2.

\section{Conclusion}

The adult second language learners of English that were examined in the present study uniformly exhibited a non-native like pattern of relative clause attachment preferences: a strong NP2 bias for the with conditions, but no attachment preference for complex genitive antecedents - the same pattern that was observed by Papadopoulou and Clahsen (2001) in L2 learners of Greek. We interpreted this as evidence that advanced L2 learners rely 
primarily on lexical-semantic information during processing, while there is no evidence from our study that they have either acquired the Recency preference for complex genitive antecedents that is found in the target language, or transferred the Predicate Proximity strategy from their L1. Monolingual English children, by contrast, appear to rely primarily on structure-based parsing strategies when resolving relative clause attachment ambiguities in their L1, while showing no evidence of being able to use lexical-semantic cues to disambiguation during processing. Taken together, these findings suggest that while children are guided by universal, least-effort based parsing principles during sentence comprehension, L2 learners attempt a more direct mapping from surface form to interpretation.

\section{Acknowledgements}

Part of the research reported here was supported by the Leverhulme Trust, which is gratefully acknowledged. We thank Harald Clahsen, Meike Hadler, Roger Hawkins, Manfred Pienemann and his research group, and the members of the Second Language Acquisition Research Group at Essex for helpful comments and discussion, and Phil Scholfield for providing statistical advice. 


\section{References}

Adams, A., \& Gathercole, S. (2000). Limitations in working memory: Implications for language development. International Journal of Language \& Communication Disorders, 35, 95-116.

Adams, B., Clifton, C. \& Mitchell, D. (1998). Lexical guidance in sentence processing? Psychonomic Bulletin and Review, 5, 265-270.

Allan, D. (1992). The Oxford Placement Test. Oxford: Oxford University Press.

Altmann, G., \& Steedman, M. (1988). Interaction with context during human sentence processing. Cognition, 30, 191- 238.

Baccino, T., De Vincenzi, M., \& Job, R. (2000). Cross-linguistic studies of the Late Closure strategy: French and Italian. In M. De Vincenzi \& V. Lombardo (Eds.), Cross-Linguistic Perspectives on Language Processsing. Dordrecht: Kluwer [pp. 89$118]$.

Baumann, H., Nagengast, J., \& Klaas, G. (1993). New Experimental Setup (NESU). Ms., Max-Planck Institute for Psycholinguistics, Nijmegen.

Booth, J., MacWhinney, B., \& Harasaki, Y. (2000). Developmental differences in visual and auditory processing of complex sentences. Child Development, 71, 981-1003.

Brysbaert, M., \& Mitchell, D. (1996). Modifier attachment in sentences parsing: Evidence from Dutch. Quarterly Journal of Experimental Psychology, 49, 664-695.

Carreiras, M., \& Clifton, C. (1993). Relative clause interpretation preferences in Spanish and English. Language and Speech, 36, 353-372.

Carreiras, M., \& Clifton, C. (1999). Another word on parsing relative clauses: Eyetracking evidence from Spanish and English. Memory and Cognition, 27, 826-833.

Corley, M. (1995). The Rôle of Statistics in Human Sentence Processing. Unpublished doctoral dissertation, University of Exeter.

Crain, S., \& Thornton, R. (1998). Investigations in Universal Grammar: A Guide to Experiments on the Acquisition of Syntax and Semantics. Cambridge, MA: MIT Press.

Crain, S., \& Wexler, K. (1999). Methodology in the study of language acquisition: A modular approach. In W. Ritchie \& T. Bhatia (Eds.), Handbook of Child Language Acquisition. San Diego: Academic Press [pp. 387-425].

Cuetos, F., \& Mitchell, D. (1988). Cross-linguistic differences in parsing: restrictions on the use of the Late Closure strategy in Spanish. Cognition, 30, 73-105.

Cuetos, F., Mitchell, D., \& Corley, M. (1996). Parsing in different languages. In M. Carreiras, J. Garcia-Albea, \& N. Sebastian-Galles (Eds.), Language Processing in Spanish. Mahwa, NJ: Lawrence Erlbaum Associates [pp. 145-187]. 
Dussias, P. (2001). Sentence parsing in fluent Spanish-English bilinguals. In J. Nicol (Ed.), One Mind, Two Languages: Bilingual Language Processing. Malden, MA: Blackwell [pp. 159-176].

Felser, C., Marinis, T, \& Clahsen, H. (submitted). Children's processing of ambiguous sentences: A study of relative clause attachment. Ms. University of Essex.

Fernández, E. (1999). Processing strategies in second language acquisition: Some preliminary results. In E. Klein \& G. Martohardjono (Eds.), The Development of Second Language Grammars: A Generative Approach. Amsterdam \& Philadelphia: John Benjamins [pp. 217-240].

Fernández, E. (2000). Bilingual sentence processing: relative clause attachment in English and Spanish. Doctoral dissertation, CUNY Graduate Center, NY.

Ferreira, F., Henderson, J., Anes, M., Weeks Jr., P., \& McFarlane, D. (1996). Effects of lexical frequency and syntactic complexity in spoken language comprehension: Evidence from the auditory moving window technique. Journal of Experimental Psychology: Learning, Memory and Cognition, 22, 324-335.

Fodor, J. D. (1998). Learning to parse? Journal of Psycholinguistic Research, 27, 285-319.

Frazier, L. (1979). On Comprehending Sentences: Syntactic Parsing Strategies, Doctoral dissertation, University of Connecticut.

Frazier, L., \& Clifton, C. (1996). Construal. Cambridge, MA: MIT Press.

Frazier, L., \& Fodor, J. D. (1978). The sausage machine: A new two-stage parsing model. Cognition, 6, 291-235.

Frazier, L., \& Rayner, K. (1982). Making and correcting errors during sentence comprehension: Eye movements and the analysis of structurally ambiguous sentences. Cognitive Psychology, 14, 178-210.

Frazier, L., \& Rayner, K. (1988). Parameterizing the language processing system: Left- vs. right branching within and across languages. In J. Hawkins (Ed.), Explaining Language Universals. Oxford: Blackwell [pp. 247-279].

Frenck-Mestre, C. (1997). Examining second language reading: An on-line look. In A. Sorace, C. Heycock \& R. Shillcok (Eds.), Proceedings of the GALA 1997 Conference on Language Acquisition. Edinburgh: Human Communications Research Center [pp. 474-478].

Frenck-Mestre, C., \& Pynte, J. (1997). Syntactic ambiguity resolution while reading in second and native languages. Quarterly Journal of Experimental Psychology, 50A, 119-148.

Frenck-Mestre, C., \& Pynte, J. (2000). Resolving syntactic ambiguities: Cross-linguistic differences? In M. De Vincenzi and V. Lombardo (Eds.), Cross-Linguistic Perspectives on Language Processing. Dordrecht: Kluwer [pp. 119-148].

Garnsey, S., Pearlmutter, N., Myers, E., \& Lotocky, M. (1997). The contribution of verb bias and plausibility to the comprehension of temporarily ambiguous sentences. Journal of Memory and Language, 37, 58-93. 
Gass, S. (1986). An interactionist approach to L2 sentence interpretation. Studies in Second Language Acquisition, 8, 19-37.

Gibson, E., \& Pearlmutter, N. (1998). Constraints on sentence comprehension. Trends in Cognitive Sciences, 2, 262-268.

Gibson, E., Pearlmutter, N., Canseco-Gonzalez, E., \& Hickok, G. (1996). Cross-linguistic attachment preferences: Evidence from English and Spanish. Cognition, 59, 23-59.

Gilboy, E., Sopena, J., Clifton, C., \& Frazier, L. (1995). Argument structure and association preferences in Spanish and English compound NPs. Cognition, 54, 131-167.

Gross, R. (2002). 'Someone shot the servant of the actress who was on the balcony.' Zur Verarbeitung von Relativsätzen im Deutschen und Englischen. MA dissertation, University of Düsseldorf.

Hahne, A. (2001). What's different in second-language processing? Evidence from eventrelated brain potentials. Journal of Psycholinguistic Research, 30, 251-266.

Hahne, A. \& A. Friederici (in press). Processing a second language: Late learners' comprehension mechanisms as revealed by event-related brain potentials. Bilingualism: Language and Cognition.

Harley, B., Howard, J., and Hart, G. (1995). Second language processing at different ages: Do younger learners pay more attention to prosodic cues to sentence structure? Language Learning, 45, 43-71.

Harrington, M. (1987). Processing transfer: Language-specific processing strategies as a source of interlanguage variation. Applied Psycholinguistics, 8, 351-378.

Harrington, M. (1992). Working memory capacity as a constraint on L2 development. In R. Harris (Ed.), Cognitive Processing in Bilinguals. New York: Elsevier [pp. 123-377].

Hawkins, R., \& Chan, C. (1997). The partial availability of Universal Grammar in second language acquisition: the 'failed functional features hypothesis'. Second Lnaguage Research, 13, 187-226.

Hemforth, B., Konieczny, L., \& Scheepers, C. (2000). Syntactic attachment and anaphor resolution: Two sides of relative clause attachment. In M. Crocker, M. Pickering \& C. Clifton (Eds.), Architectures and Mechanisms for Language Processing, Cambridge: Cambridge University Press.

Henstra, J.-A. (1996). On the Parsing of Syntactically Ambiguous Sentences: Coordination and Relative Clause Attachment. Unpublished doctoral dissertation, University of Sussex.

Hernández, A., Bates, E., \& Avila, L. (1994). On-line sentence interpretation in SpanishEnglish bilinguals: What does it mean to be 'in between'? Applied Psycholinguistics, 15, 417-446.

Hurewitz, F., Brown-Schmidt, S., Thorpe, K., Gleitman, L., \& Trueswell, J. (2000). One frog, two frog, red frog, blue frog: Factors affecting children's syntactic choices in production and comprehension. Journal of Psycholinguistic Research, 29, 597-626. 
Juffs, A. (1998). Main verb vs reduced relative clause ambiguity resolution in second language sentence processing. Language Learning, 48, 107-147.

Juffs, A., \& Harrington, M. (1995). Parsing effects in second language sentence processing: Subject and object asymmetries in wh-extraction. Studies in Second Language Acquisition, 17, 483-516.

Just, M., Carpenter, P., \& Woolley, J. (1982). Paradigms and processes in reading comprehension, Journal of Experimental Psychology: General, 111, 228-238.

Kilborn, K. (1989). Sentence processing in a second language: The timing of transfer. Language and Speech, 32, 1-23.

Kilborn, K. (1992). On-line integration of grammatical information in a second language. In R. Harris (Ed.), Cognitive Processing in Bilinguals. New York: Elsevier [pp. 337351].

Kilborn, K., \& Ito, T. (1989). Sentence processing strategies in adults bilinguals. In B. MacWinney \& E. Bates (Eds.), The Crosslinguistic Study of Sentence Processing. Cambridge: Cambridge University Press [pp. 257-291].

MacWhinney, B. (1987). The Competition Model. In B. MacWhinney (Ed.), Mechanisms of Language Acquisition. Hillsdale, NJ: Erlbaum [pp. 249-308].

MacWhinney, B. (1997). Second Language Acquisition and the Competition Model. In A. De Groot \& J. Kroll (Eds.), Tutorials in Bilingualism: Psycholinguistic Perspectives. Mahwah, NJ: Erlbaum.

MacWhinney, B. (2001). Extending the competition model. In R. Heredia \& J. Altaririba (eds.), Bilingual Sentence Processing.

Mazuka, R. (1998). The Development of Language Processing Strategies. A CrossLinguistic Study Between Japanese and English. Hove: Lawrence Erlbaum Associates.

Mazuka, R., \& Lust, B. (1990). On parameter setting and parsing: Predictions for crosslinguistic differences in adult and child processing. In L. Frazier \& J. de Villiers (Eds.), Language Processing and Language Acquisition. Dordrecht: Kluwer.

McDonald, J. (1987). Sentence interpretation in bilingual speakers of English and Dutch. Applied Psycholinguistics, 8, 379-413.

Mitchell, D., \& Cuetos, F. (1991). The origins of parsing strategies. In C. Smith (Ed.), Current Issues in Natural Language Processing. Center for Cognitive Science, University of Austin, TX [pp. 1-12].

Papadopoulou, D., \& Clahsen, H. (2001). Parsing strategies in L1 and L2 sentence processing: A study of relative clause attachment in Greek. Ms., University of Essex.

Pienemann, M. (1998). Developmental dynamics in L1 and L2 acquisition: Processability Theory and generative entrenchment. Bilingualism: Language and Cognition, 1, 120 . 
Ritchie, W., \& T. Bhatia (Eds.). (1996). Handbook of Second Language Acquisition. San Diego, CA: Academic Press.

Ritchie, W., \& T. Bhatia (Eds.). (1999). Handbook of Child Language Acquisition. San Diego: Academic Press.

Roberts, L. (in progress). Syntactic Processing in Learners of English. Doctoral dissertation, University of Essex.

Schafer, A., Carter, J., Clifton, C., \& Frazier, L. (1996). Focus in relative clause construal. Language and Cognitive Processes, 11, 135-163.

Snedeker, J., \& Trueswell, J. (2001). Unheeded cues: Prosody and syntactic ambiguity in mother-child communication. Paper presented at the $26^{\text {th }}$ Annual Boston University Conference on Language Development, 2-4 November 2001.

Tanenhaus, M., Spivey-Knowlton, M., Eberhard, K., \& Sedivy, J. (1995). Integration of visual and linguistic information in spoken language comprehension. Science, 268, 1632-1634.

Thornton, R., MacDonald, M., \& Gil, M. (1999). Pragmatic constraints on the interpretation of complex noun phrases in Spanish and English. Journal of Experimental Psychology: Learning, Memory, and Cognition, 25, 1347-1365.

Traxler, M. (2002). Plausibility and subcategorization preference in children's processing of temporarily ambiguous sentences: Evidence from self-paced reading. Quarterly Journal of Experimental Psychology, 55A, 75-96.

Traxler, M., Pickering, M, \& Clifton, C. (1998). Adjunct attachment is not a form of lexical ambiguity resolution. Journal of Memory and Language, 39, 558-592.

Trueswell, J., Sekerina, I., Hill, N., \& Logrip, M. (1999). The kindergarden-path effect: Studying on-line sentence processing in children. Cognition, 73, 89-134.

Valian, V. (1990). Logical and psychological constraints on the acquisition of syntax. In L. Frazier \& J. de Villiers (Eds.), Language Processing and Language Acquisition. Dordrecht: Kluwer [pp. 119-145].

VanPatten, B. (1996). Input Processing and Grammar Instruction in Second Language Acquisition. Norwood, NJ: Ablex.

Ying, H. (1996). Multiple constraints on processing ambiguous sentences: Evidence from adult L2 learners. Language Learning, 46, 681-711.

Zagar, D., Pynte, J., \& Rativeau, S. (1997). Evidence for early-closure attachment on firstpass reading times in French. Quarterly Journal of Experimental Psychology, 50A, 421-438. 
Notes

1 Note, however, that some on-line studies have failed to replicate the above finding or have produced mixed results (Carreiras \& Clifton, 1993, Traxler, Pickering, \& Clifton, 1998).

Gibson et al. (1996) hypothesize that the relative strength of the Predicate Proximity strategy may be linked to the degree of (non-)configurationality of a given language. That is, in languages such as Spanish, German or Greek which allow verbs and their complements to be non-adjacent, the verb may be more 'active' during processing than it is in a highly configurational language such as English, and hence may be more likely to attract ambiguous modifiers.

$3 \quad$ Snedeker and Trueswell (2001) report results from a communication task indicating that 5 year-old children also fail to make use of prosodic cues when processing PPattachment ambiguities.

Preliminary results from a series of off-line and on-line experiments carried out by Roberts (in progress) demonstrate that the relative order of the two potential host NPs by itself has no effect on attachment. Any differences in disambiguation preferences found between the of and the with conditions must therefore be due to lexical properties of the preposition, or to the relationship between the two NPs that the preposition signals.

5 All our experimental materials can be made available upon request.

6 Note that the results from the grammaticality judgement test with the Greek participants should not be compared directly with those from the grammaticality judgement task carried out with the German L2 learners (cf. section 5), as both the materials and the scoring procedure were different. The materials for the Greeks also included relative clause constructions deemed particularly difficult for Greek learners of English to judge such as The children that their mother works as a teacher are very naughty, which are grammatical in Greek. In conjunction with the fact that the participants could provide scaled rather than absolute judgements, and that we did not use a 'forced choice' procedure, this may account for the Greek participants' slightly lower scores in this task.

7 This hypothesis would also account for the German learners' relatively longer reading times on the 'wrap-up' segment in the of conditions in Experiment II. Note, however, that the results from the Greek learners do not show any effect of Preposition on this segment.

Contact E-mail:felsec@essex.ac.uk 